\title{
PERSONAGEM E FENÔMENO FANTÁSTICOS: A DIALÉTICA DE JOËL MALRIEU EM FERIADO DE MIM MESMO, DE SANTIAGO NAZARIAN
}

Márcio Henrique de Almeida Soares (UEL)

Recebido em 03 out 2017. Márcio Henrique de Almeida Soares é Graduado em Aprovado em 24 out 2017.

Comunicação Social com habilitação em Publicidade e Propaganda pela Faculdade Pitágoras de Londrina (2012). Mestre em Literatura Comparada pela Universidade Estadual de Londrina (2017). Atualmente cursando Letras Estrangeiras Modernas, com habilitação em língua e literatura inglesa na Universidade Estadual de Londrina e Doutorado em Literatura Comparada pela mesma instituição. Interessado em ensino de línguas e literatura e no estudo de narrativas insólitas, especialmente da narrativa fantástica no século XIX e na contemporaneidade.

Resumo: Joël Malrieu, em Le fantastique (1992), atribui o núcleo da narrativa fantástica à dialética, o embate, entre uma personagem regular e um fenômeno extraordinário que com ela entra em contradição. Partindo desse pensamento e do pressuposto de que o fantástico, segundo o modelo estudado por Malrieu, ainda se faz presente na contemporaneidade, buscamos investigar a manifestação dessa dialética no romance Feriado de mim mesmo (2005), de Santiago Nazarian. Para tal, nos utilizamos, além do aparato teórico, de uma análise comparativa entre a obra em questão e diversos textos fantásticos do século XIX, 
época de maior projeção desse tipo de literatura. Assim, esperamos compreender as implicações da dialética de Malrieu em Feriado de mim mesmo, bem como em que grau o romance de Nazarian se aproxima ou se distancia desse modelo tradicional de fantástico, oferecendo, deste modo, indícios de que a obra em questão possa ser classificada como narrativa fantástica.

Palavras-chave: Santiago Nazarian; Feriado de mim mesmo; Joël Malrieu; Fantástico.

Abstract: Joël Malrieu, in Le fantastique (1992), attributes the core of fantastic narrative to the dialectic, the clash, between a regular character and an extraordinary phenomenon that with it comes into contradiction. Based on this thought and in the assumption that the fantastic, according to the model studied by Malrieu, is still present in contemporary literature, we seek to investigate the manifestation of this dialectic in the novel Feriado de mim mesmo (2005), by Santiago Nazarian. In order for doing so, we will work with, in addition to the theoretical apparatus, a comparative analysis between the aforementioned book and several fantastic texts from the nineteenth century, a time of great prominence for this type of literature. Thus, we expect to comprehend the implications of Malrieu's dialectic on Feriado de mim mesmo, as well as to what degree Nazarian's novel approaches or distances itself from the traditional fantastic model, providing evidence that this work may possibly be classified as a fantastic narrative.

Keywords: Santiago Nazarian; Feriado de mim mesmo; Joël Malrieu; Fantastic.

\section{INTRODUÇÃO}

Em sua obra Le fantastique (1992), Joël Malrieu aponta como traço fundamental do fantástico, presente nas narrativas do século XIX tidas como cânone dessa vertente literária, não a hesitação proposta por 
Tzvetan Todorov em Introdução à literatura fantástica (1975), mas a dialética entre personagem e fenômeno. Para o autor francês,

o conto fantástico se apoia, essencialmente, na confrontação entre um personagem isolado com um fenômeno, exterior a ele ou não, sobrenatural ou não, mas cuja presença ou intervenção representa uma contradição profunda entre os modos de pensamento e de vida do personagem, ao ponto de modificá-los completamente e de forma duradoura. (MALRIEU, 1992, p.49 - tradução nossa) ${ }^{1}$

É através da interação entre um indivíduo comum, vivendo em um mundo como o nosso, e um fenômeno extraordinário, em evidente conflito com aquilo que a personagem conhece, pensa e toma como verdadeiro ou certo, que surge o relato fantástico. Esse diálogo fomenta, inevitavelmente, profundas transformações na personagem que pode ir da calma à violência, da racionalidade à loucura, do ceticismo à crença, etc. Tudo isso teria como principal função gerar uma tomada de consciência da personagem, uma superação da alienação - em relação à sua própria realidade - à qual ela está submetida antes do encontro com o fenômeno. Essa tomada de consciência, entretanto, nem sempre ocorre, posto que, ainda que o fenômeno evidencie as contradições da realidade em que a personagem vive, esta pode preferir negar-se a reconhecer a legitimidade da revelação.

Pensando nessas questões, este trabalho tem como principal objetivo trazer o pensamento de Malrieu para uma obra contemporânea em que se identifica traços relevantes do que se tomou tradicionalmente como fantástico. $\mathrm{O}$ romance Feriado de

1 Le récit fantastique repose en dernier ressort sur la confrontation d'un personnage isolé avec un phénomène, extérieur à lui ou non, surnaturel ou non, mais dont la présence ou l'intervention représente une contradiction profonde avec les cadres de pensée et de vie du personnage, au point de les bouleverser complètement et durablement. 
mim mesmo (2005), do autor brasileiro Santiago Nazarian, conta a história de um jovem tradutor, Miguel, que vive só em um apartamento de dois quartos e que possui vida social praticamente nula, evitando obstinadamente o convívio com outras pessoas. Subitamente, a personagem passa a notar indícios de que um intruso invade repetidamente seu apartamento, deixando uma escova de dentes nova no banheiro, comendo sua comida, gravando arquivos em seu computador. Não conseguindo encontrar mais do que pistas da atividade desse outro, a personagem passa a buscar, de forma incessante, a confrontação. Quando esse embate finalmente acontece, a personagem está convencida de que seu rival, cuja aparência é extremamente parecida com a sua, é uma assombrosa materialização de sua consciência. A partir daí, Miguel se sente livre para um ato homicida e canibal que visa devolver-Ihe a parte perdida de si. Somente no fim do romance descobrimos que o intruso é, na verdade, Thomas Schimidt, o namorado que o protagonista apagou completamente de sua memória.

Para realizar tal estudo, nos valeremos não só da obra de Malrieu, mas também de outras teorias do fantástico, em paralelo a um estudo comparativo da personagem e do fenômeno conforme apresentados nas narrativas fantásticas do século XIX. Dividiremos o trabalho em duas seções, cada uma com enfoque maior em uma das partes envolvidas na história, mas sempre considerando a relação dialética entre ambas.

\section{MIGUEL}

Em se tratando da personagem fantástica, Joël Malrieu (1992) afirma que ela necessita aparentar ser ordinária, comum, de modo 
a facilitar sua identificação na própria sociedade que o mundo ficcional busca representar. Convém lembrar, aqui, que Todorov (1975) já dizia que o mundo do fantástico é o nosso mundo, sendo assim, a personagem deve se assemelhar a um indivíduo que habita nossa realidade. Ocorre, no entanto, que essa mediocridade, como coloca Malrieu, esse caráter superficial e indeterminado da personagem fantástica, mascara uma série de condições muito específicas e fundamentais para que ela possa desempenhar sua função no jogo que estabelece com o fenômeno. A personagem, como postula Furtado em A construção do fantástico na narrativa (1980), por exemplo, deve incluir-se em um extrato social que goze de credibilidade frente à sociedade à qual pertence. Deste modo, geralmente, a personagem fantástica faz parte de uma elite intelectual e cultural, o que a torna suficientemente respeitável para que, quando do encontro com o fenômeno, sua palavra seja levada em consideração mesmo que os acontecimentos pareçam virtualmente impossíveis.

É o que se verifica em "O sinaleiro", de Dickens. Na história, o narrador visita repetidas vezes um sinaleiro - um funcionário responsável por avisar os trens sobre perigos na ferrovia - em seu posto, que se localiza próximo a um túnel, em um local isolado, situado entre dois enormes paredões de pedra. O homem parece atormentado e alega ter premonições sobre acidentes na ferrovia. Ele conta suas premonições, que se constituem pelo som de batidas de sinos sem que eles estejam realmente tocando e a visão de um espectro próximo ao túnel. Pouco tempo após cada aparição, trágicos acidentes ocorreram. Uma semana antes da visita do narrador, o espectro havia tornado a aparecer ocasionalmente e o 
sinaleiro demonstra-se aflito com a possibilidade de um acidente que ele sente não poder evitar. Por fim, o próprio trabalhador morre em um acidente na ferrovia. Embora o sinaleiro seja um homem humilde, ele não é descrito como supersticioso e revela, além do interesse por línguas e do estudo autodidata de matemática, uma educação formal: "Quando moço [...] fora um estudante de filosofia natural e assistira a palestras" (DICKENS, 2004, p.302).

Em Feriado de mim mesmo, temos também um protagonista, escritor e tradutor, pertencente a uma elite intelectual no Brasil de nossos dias e plenamente condizente com as definições de Furtado e Malrieu. Outra relação entre "O sinaleiro" e Feriado que possui influência direta sobre a constituição da personagem fantástica é o isolamento social que, em um, se dá por questões profissionais e geográficas e, em outro, voluntariamente através da escolha de morar sozinho e evitar se relacionar com outras pessoas mesmo em meio a uma grande cidade. Em ambos os casos, as personagens estão distantes do mundo do trabalho tradicionalmente conhecido, não tendo de lidar diretamente e diariamente com chefes e colegas, por exemplo: "Se o personagem é a esse ponto privado de qualquer laço social, é porque o fantástico visa um indivíduo desligado de toda determinação exterior, uma espécie de homem em si mesmo" (MALRIEU, 1992, p.57- tradução nossa)².

Também por essa mesma razão, a personagem fantástica vive ainda um isolamento intelectual e afetivo. Em Feriado, toda a família de Miguel mudou-se para a Argentina e ele vive sozinho em seu apartamento sem receber qualquer companhia de amigos ou

2 Si le personnage est à ce point privé de toute attache sociale, ce parce que le fantastique envisage toujours un individu coupé de toute détermination extérieure, un sorte d'homme en soi. 
amantes. Não há ninguém com quem a personagem possa discutir assuntos filosóficos ou mesmo cotidianos, não há debate intelectual. Convém notar que, apesar da presença da internet no romance, ela exerce um papel altamente pontual, não servindo para que o protagonista troque mais que alguns e-mails com sua família e com Thomas, a quem, no momento da correspondência, ele considera ser sua consciência materializada. Miguel também deixa claro que, embora em alguns momentos pareça sentir falta de uma companhia, não possui qualquer intenção de se relacionar afetivamente com alguém: "Se o interesse era sexo, poderia conseguir a qualquer hora. Numa esquina qualquer, na avenida Farrapos, pela Internet, nos bares, na noite, num gole a mais, ou num gole a menos. Não precisava fazer promessas, nem trocar telefones" (NAZARIAN, 2005, p.23). Essa solidão é emblemática do fantástico e podemos pensar, ainda, no relacionamento que Miguel tem com Thomas e do qual se esquece completamente. Se a solidão não existe, ela é criada haja vista que "[o] fenômeno separa até os casais mais unidos" (MALRIEU, 1992, p.59 - tradução nossa) ${ }^{3}$. O fenômeno se interpõe entre a personagem e qualquer relacionamento com outras pessoas, gerando um inevitável isolamento.

Em "The phantom 'rickshaw", de Rudyard Kipling (1888-1890), o fenômeno desempenha o mesmo papel de separar o casal. Na história, Pansay, um inglês vivendo na Índia, envolve-se com uma mulher casada, senhora Wessington, e ela por ele se apaixona. Passado um tempo, Pansay perde o interesse pela mulher, mas ela não deixa de procurá-lo, a fim de uma reconciliação. Posteriormente, o rapaz se apaixona por uma jovem e eles se

3 Le phénomène sépare les couples les plus unis. 
tornam noivos. A senhora Wessington, que já definhava por conta do desdém de Pansay, acaba falecendo e o jovem começa a ter visões suas justamente quando decide comprar um anel de noivado para sua amada. A falecida surge sempre do mesmo modo que o antigo amante a vira pela última vez, sentada em seu riquexó - carruagem puxada por trabalhadores, comum na Índia - e fala as mesmas palavras que havia dito em seu último encontro. Pansay é cada vez mais afetado pelas aparições, até que isso ocasiona o término de seu noivado e, por fim, sua morte. Em suas últimas semanas de vida, Pansay passa a cavalgar e conversar com a aparição, sendo tido por louco pelas pessoas que o veem, isolando-se do mundo.

Mais um traço comum à personagem fantástica é a demonstração de certo ceticismo. É o que vemos em Pansay, do conto de Kipling, que afirma sobre seu próprio relato: "[d]ois meses atrás, eu teria repudiado e considerado louco ou bêbado o homem que se atrevesse a me contar algo assim" (1888-1890, p.9 - tradução nossa) ${ }^{4}$. É comum também que essa personagem, mesmo frente aos maiores indícios, busque possíveis explicações naturais para o acontecimento, pois "a demonstração de uma certeza absoluta da existência da fenomenologia insólita poderá contribuir para remeter a narrativa para o maravilhoso" (FURTADO, 1980, p.103). Deste modo, a narrativa fantástica visa simular um esgotamento de alternativas para que a personagem possa, em alguns casos, aceitar o insólito, ou, em outros casos, se manter em dúvida. Esse papel pode ser inteiramente conduzido pelo protagonista ou, raras

4 Two months ago I should have scouted as mad or drunk the man who had dared to tell me the like. 
vezes, diluído entre este e um ou mais personagens secundárias como ocorre no conto de Kipling. Pansay não demora muito para se entregar à ideia de que suas visões são realmente manifestações da falecida amante. O doutor Heatherlegh, no entanto, mantém o diagnóstico de que tudo não passa de uma ilusão e o jovem é gradualmente persuadido por essa noção: "eu me tornei mais e mais inclinado a aceitar a teoria de Heatherlegh de que tudo não passava de uma 'ilusão espectral' relacionada a olhos, cérebro e estômago" (KIPLING,1888-1890, p.22 - tradução nossa)5. Pansay concorda com essa versão até que o tratamento do médico se prova infrutífero e ele aceita de vez a sobrenaturalidade do fenômeno.

Um expediente diferente é utilizado em Feriado, visto que personagens secundárias tem pouquíssimo espaço no livro. É o próprio Miguel com suas conjecturas e suposições que proporciona o questionamento do fenômeno. Miguel se esforça por elaborar uma série de explicações para os acontecimentos considerando desde possíveis descuidos seus até a invasão de um funcionário do Inmetro, cujo pátio se situa em frente à janela de seu quarto. Tendo, aparentemente, analisado todas as interpretações plausíveis, Miguel parte então para uma explicação sobrenatural: a materialização de sua consciência. O que só chegamos a saber depois é que Miguel ignorou e continua a ignorar, mesmo ao fim do romance, o apagamento completo de seu namorado da memória. O que notamos nesse percurso é que há a tentativa de aparentar esgotamento das possibilidades naturais apoiada em um honesto exercício intelectual por parte da personagem. Lembramos, aqui,

5 I became more and more inclined to fall in with Heatherlegh's "spectral illusion" theory, implicating eyes, brain and stomach. 
do que Furtado (1980) chama de falsidade verossímil e Bessière (1974) de falsidade intelectual; sobre o assunto, a pesquisadora francesa diz que o fantástico "faz da ilusão a maneira de conferir certa inocência [...] a constantes espantos e surpresas; ele reconstrói um ato de descoberta" (BESSIÈRE, 1974, p.29 - tradução nossa) ${ }^{6}$. Sendo assim, Miguel não aceita de imediato a sobrenaturalidade do fenômeno, mas é levado a conclusões nesse sentido de forma aparentemente inevitável. A personagem "descobre" o sobrenatural a partir de indícios da realidade que contradizem mesmo as expectativas dos mais céticos e, assim, conforme dito por Malrieu, revela seus próprios limites.

Convencido da materialidade da manifestação meta-empírica, o protagonista pode recorrer a outras personagens a fim de obter comprovação ou auxílio no enfrentamento do problema. Acontece que, como vimos em "The phantom 'rickshaw", na maioria das vezes, seu relato é tido como algum tipo de ilusão, o que pode, de início, levá-lo a duvidar de suas convicções, mas, por fim, acaba por conduzir ou reconduzir o protagonista a seu isolamento social.

Em "O caso do finado Mr. Elvesham", de H. G. Wells, temos um exagero dessa situação, em que a personagem principal recorre a diversas pessoas e acaba interditada como insana devido a seu relato. No conto, o jovem Edward George Eden é abordado por um velho e rico filósofo de nome Egbert Elvesham que diz estar à procura de um jovem íntegro e de boa saúde para deixar a ele toda sua fortuna. Eden é logo persuadido a aceitar os termos de Elvesham para herdar os seus bens, o que consistia no escrutínio de sua vida

6 fait de l'illusion le moyen de rendre une certaine naïveté [...] à d'incessants étonnements et surprises; il reconstruit une activité de découverte 
pessoal e na realização de diversos exames médicos. Finalmente, os dois selam o acordo em um jantar, durante o qual o filósofo oferece a Eden uma bebida em que é colocado um pó rosado. Mr. Elvesham ainda entrega ao jovem, antes de se despedirem, outro pó que deve ser consumido antes de dormir para que ele não sofra com dores de cabeça no dia seguinte. Eden toma o pó com água e, no dia seguinte, acorda no corpo do filósofo. Desesperado, tenta buscar auxílio, mas é contido pelos próprios funcionários da casa de Elvesham, onde se encontra: "Ninguém acredita em mim. Sou tratado como um demente e, mesmo agora, mantido sob vigilância" (WELLS, 2013, p.411). Escrever o relato é, para Eden, uma forma de provar sua lucidez e reconstituir tudo o que passou, uma forma de contar para o mundo a história em que ele acredita piamente e obter, talvez, a simpatia e solidariedade de alguém.

Embora não da forma extrema como é abordada no conto de Wells, uma situação parecida ocorre em Feriado de mim mesmo quando Miguel chama a polícia com o objetivo de capturar o invasor que ele acredita estar em sua casa. Miguel teve sérios indícios de que havia alguém no apartamento, no entanto, quando a polícia chega, não há ninguém além do protagonista. Os policiais inspecionam o apartamento, mas não encontram invasor algum e saem de lá convencidos de que tudo não passou de um delírio. Miguel é, assim, posto em descrédito frente a uma forte instituição social, aprofundando seu isolamento: "Fora longe demais. Chamara os policiais. E continuava sem respostas, ameaçado, tendo de se defender sozinho de uma ameaça sem rosto" (NAZARIAN, 2005, p.94).

Essa cena, aliás, está profundamente relacionada ao caráter de thriller assumido por Feriado e denuncia a hibridização 
sofrida pelo fantástico ao longo do tempo. Durante boa parte da história, temos a ideia de que Miguel, uma pessoa extremamente comum e sem grandes problemas, enfrenta um invasor em seu apartamento, característica típica da trama policial. Acontece que, logo, essa percepção muda especialmente pelo posicionamento da personagem. Como diz Malrieu, no romance policial, temos

um herói, fenomenal como deve ser por definição, confrontado com um fenômeno, de modo que testemunhamos uma espécie de luta maniqueísta entre o herói fenomenal [...] e o fenômeno, e não à dialética do personagem e do fenômeno constitutivos do conto fantástico. (1992, p.67 tradução nossa) ${ }^{7}$

Heróis como Sherlock Holmes estão em um nível acima daqueles que enfrentam, seja intelectualmente, seja moralmente ou, ainda, em termos de controle e poder; eles são plenos em si e "caçam" o fenômeno em uma clara luta do bem contra o mal. Miguel inicia o romance de um modo muito próximo a esse herói fenomenal, mas se mostra gradualmente mais problemático e é do confronto entre suas ações e as de Thomas que se dá o desenvolvimento da história. A relação entre personagem e fenômeno no fantástico é muito mais complexa do que a simples dinâmica "caça e caçador", é o confronto instável entre dois mundos que se chocam e se transformam continuamente.

É a partir desse confronto que uma nova verdade se apresenta a Miguel e aprofunda a fragmentação de sua personalidade. A

7 un héros, phénoménal comme il se doit par définition, confronté à un phénomène, de sorte que nous assistons ici à une sorte de lutte manichéenne entre le héros phénoménal [...] et le phénomène, et non à la dialectique du personnage e du phénomène constitutive du récit fantastique. 
cada nova interação, ele se distancia mais e mais de sua posição inicial na história e adentra um universo de paranoia e loucura. A projeção da própria consciência no fenômeno é justamente um grande indicativo desse sentimento de perda do "eu". Sentindose incapaz de vencer seu adversário e considerando já impossível a vida em seu apartamento, então, Miguel tenta fugir tal qual o faz a personagem-título de "William Wilson", de Edgar Allan Poe (2016). Nessa história, o narrador se revela uma pessoa aproveitadora e de poucos escrúpulos que se vê às voltas, desde a infância, com um outro que possui o mesmo nome que o seu, tem a mesma aparência e até nasceu no mesmo dia. O rival se contrapõe constantemente ao narrador fazendo com que este se sinta, não raramente, constrangido. O outro persegue William Wilson por toda a vida adulta expondo-o a situações cada vez mais vergonhosas até que sua reputação se torna tão humilhante que ele decide fugir para outros países, sem, entretanto, conseguir escapar de seu perseguidor que sempre o encontra onde quer que vá, até seu último enfrentamento. De forma parecida, Miguel tenta fugir para a Argentina, mas acaba retornando ao apartamento para seu confronto final com Thomas. No momento do confronto, em ambas histórias, temos um ápice de loucura, pois esta é "uma das formas mais extremas da perda de identidade" (MALRIEU, 1992, p.71 - tradução nossa) ${ }^{8}$ típica da personagem fantástica.

Nesse ponto, Miguel e Wilson discutem com seus opositores e se aproximam, finalmente, de um conhecimento inesperado de si mesmos. Thomas revela que ele é, de fato, outro: "Eu voltei de viagem e o apartamento estava esta zona. Voltei e você mal reparou em mim.

8 une des formes les plus extrêmes de la perte d'identité. 
Não sei se você encontrou outra pessoa. Não sei se você exagerou nas drogas. Só sei que você precisa de um tempo pra pensar, e eu também" (NAZARIAN, 2005, p.136-137). Thomas levanta, ainda, a possibilidade de que Miguel tenha enlouquecido. Da mesma maneira, Wilson revela ao narrador - que está bêbado nesse momento e, portanto, em estado alterado de consciência tal como, possivelmente, Miguel-que eles são, na verdade, a mesma pessoa. A realidade é entregue, pelo fenômeno, às personagens, revelando suas falhas. Em algumas narrativas, como "The phantom 'rickshaw", em que Pansay percebe seus equívocos e abraça seu destino, isso é suficiente para que a personagem atinja um novo nível de consciência. Em outras, como o conto de Poe e o romance de Nazarian, esse desfecho não se realiza: "[O] personagem nem sempre acessa a consciência desta revelação" (MALRIEU, 1992, p.72-73 - tradução nossa) ${ }^{9}$.

Assim, tentando assassinar o outro, Wilson assassina a si mesmo. Por sua vez, tentando assassinar uma parte de si, Miguel assassina um outro. Em ambos os casos, a morte representa o fim de toda uma realidade que as personagens negam sobre si mesmas. Os erros de Wilson e os fracassos de Miguel - cujo namorado era um escritor de sucesso, enquanto ele era um tradutor sem nenhum prestígio, além de aspirante a autor -, são banhados em sangue e negação. A negação das próprias falhas de caráter, no caso de Wilson, e a negação da própria homossexualidade, no caso de Miguel. A personagem de Poe quer destruir a fração de seu ser que acusa sua responsabilidade pelos próprios malfeitos. A personagem de Nazarian quer destruir o objeto de seu desejo na esperança de que, assim, possa destruir o próprio desejo.

9 le personnage n'accède pas toujours à la conscience de cette révélation 


\section{THOMAS}

Chegamos, então, ao fenômeno, que é mais que um simples evento ou acontecimento, embora seja muitas vezes assim chamado. Trata-se de uma presença robusta e pulsante na narrativa fantástica que dialoga com o protagonista em um rito de desvelamento da realidade. É justamente a partir de sua origem aparentemente não-natural que o fenômeno possibilita à personagem fantástica a descoberta de uma nova leitura de mundo. Ainda assim, de início, o fenômeno mantém um caráter bastante comum em muitos de seus aspectos, assemelhando-se àquilo que consideramos humano: "O fenômeno não apresenta, à primeira vista, nada de inquietante em si mesmo" (MALRIEU, 1992, p.81 - tradução nossa) ${ }^{10}$. Ele também não demonstra qualquer evolução ao longo da história, o que muda é a percepção da personagem a seu respeito. Thomas, de Feriado de mim mesmo, é a perfeita representação dessa configuração narrativa. Suas intervenções iniciais na história - a escova de dentes, o frango comido, etc - são pouco ou nada ameaçadoras. Além disso, de início, Miguel o percebe como um intruso de carne e osso, um invasor, e só depois avança na direção de uma concepção sobrenatural desse fenômeno. No fim, Thomas era apenas um homem como outro qualquer e nenhuma de suas características se altera, seja no sentido de não se tornar sobrenatural, seja no sentido de não ocorrer qualquer mudança em sua personalidade ou percepção de mundo. Enquanto Miguel se transforma do que parecia ser um jovem independente e pouco sociável para um territorialista paranóico, Thomas permanece o mesmo que era desde o início da narrativa.

10 Le phénomène ne présente à première vue rien d'inquiétant en soi. 
The picture of Dorian Gray, de Oscar Wilde (2015), brinca com essa situação, trazendo um fenômeno que, aparentemente, se modifica enquanto a personagem permanece inalterada. $\mathrm{Na}$ história, Basil Hallward pinta o retrato de Dorian, um belíssimo jovem por quem o pintor sente grande admiração. Surge, então, Lorde Henry Wotton, amigo de Basil, que incute em Dorian uma série de pensamentos antes ocultos a ele, especificamente em relação à brevidade de sua beleza. Com isso, Dorian sofre um choque de realidade e deseja que o retrato receba as marcas do tempo em seu lugar: "Se fosse eu a permanecer para sempre jovem e o retrato a envelhecer! Por isto - por isto - eu daria qualquer coisa!" (WILDE, 2015, p.26 - tradução nossa) ${ }^{11}$. Seu desejo parece se realizar posto que, por mais que os anos passem e sua personalidade se torne cada vez mais cruel e distorcida, sua beleza não se esvanece enquanto a imagem no quadro parece receber as transformaçõesque a ele caberiam. A trama caminha com base nessas transformações até que Dorian, na tentativa de destruir o quadro e livrar-se daquela imagem que denunciava a corrupção de sua alma, acaba perdendo a própria vida. Por esse resumo, percebemos que, na verdade, embora fisicamente as alterações sejam invertidas, é a personalidade da personagem que se altera, enquanto a condição sobrenatural do retrato permanece até o fim do romance. De qualquer modo, Dorian também carrega algo de fenômeno já que é uma parte dele que se deposita na imagem e é um aspecto da imagem que ele toma para si. Da mesma maneira, Miguel também carrega uma parte de Thomas posto que os dois eram namorados e extremamente parecidos fisicamente. Além 11 If it were I who was to be always young, and the picture that was to grow old! For that - for that - I would give everything! 
disso, é através dos olhos do protagonista que experimentamos o acontecimento que, no fim, descobrimos ser uma ilusão, ou seja, o fenômeno se dá a partir da percepção de Miguel e, portanto, é ele próprio também o fenômeno.

Como coloca Malrieu, nota-se, assim, que o fenômeno é uma projeção da personagem, representando, no romance de Wilde, a materialização da maior aspiração de Dorian, a juventude eterna. Já em Feriado, inversamente, o fenômeno representa o maior temor de Miguel, sua homossexualidade, visto que, no final do livro, Miguel se nega a acreditar que seja homossexual mesmo diante de diversas provas apontadas por seu advogado. Thomas, seria, assim, como já dissemos, a materialização do desejo homossexual reprimido por Miguel. Mesmo se considerarmos a dificuldade do protagonista em lidar com a interação humana, buscando e rejeitando a solidão ao mesmo tempo, tudo parece sempre retornar a um mesmo problema que é a convivência consigo mesmo, principalmente com aquilo que se é e não com aquilo que se gostaria de ser: " $E$ se via trancado naquela vida. Trancado naquele apartamento, condenado a si próprio. Sem ter por que dormir, nem tampouco por que acordar. Livre e condenado, condenado às suas próprias escolhas" (NAZARIAN, 2005, p.104). A dificuldade de aceitação do "eu" inviabiliza a Miguel a aceitação do outro, especialmente a parte de si que ele percebe nesse outro, nesse seu duplo.

O duplo, aliás, é um tema central no romance de Nazarian e exprime muito sobre o fenômeno, especialmente no que diz respeito a seu caráter conflitivo. Segundo Berenice Sica Lamas, o duplo se manifesta através de uma variada gama de representações como a sombra, o sósia ou a alma e "[c]onstrói-se através de processos 
como cisão do eu, metamorfose e narcisismo, que aparecem nas diferentes representações" (2004, p.47). Tanto o primeiro quanto o terceiro processo se revelam claramente em Feriado posto que Miguel é um ser fragmentado, perdido entre seus desejos, memórias e medos, mas é também um homem cujo namorado carrega com ele uma semelhança perturbadora, denunciando uma relação inegavelmente narcisista. Reconhecendo a grande multiplicidade e mutabilidade do duplo ao longo do tempo e nos mais diversos gêneros literários, Adilson dos Santos afirma:

A única coisa que, seguramente, pode-se dizer é que, independentemente da diversidade de realizações e representações, as histórias de duplo geralmente apresentam uma face invariável de impasse, propiciadora de um sentimento de insegurança e mistério, nem sempre totalmente decifrável, nem sempre de compreensão plena. (2009, p.54)

É justamente esse aspecto desafiador que torna o duplo tão conveniente à literatura fantástica, permitindo a inserção de uma instabilidade única, tão adequada a esse tipo de narrativa. Ocorre que, mesmo sendo um tema historicamente recorrente na literatura mundial e profundamente ligado à subjetividade, no fantástico, o duplo assume um caráter ainda mais introspectivo, "o tema é fortemente interiorizado, e ligado à vida da consciência, das suas fixações e projeções [...], da duplicação obscura que cada indivíduo joga para trás de si, na sua sombra" (CESERANI, 2004, p.83).

Feriado de mim mesmo comprova essa teroria. Tudo o que se passa na história está diretamente ligado aos pensamentos, sentimentos e emoções de Miguel, tudo é parte da sua vida mental, 
mesmo aquilo que, a princípio, não deveria ser. Thomas é tragado, no livro, pela mente perturbada de Miguel e acaba se tornando uma simples manifestação de sua consciência ao invés de um ser humano. Sua humanidade só é indicada quando a polícia prende Miguel por seu crime e reconhecida depois, no epílogo, quando o protagonista é confrontado por seu advogado. Durante a maior parte da trama, esse duplo é a projeção dos medos de Miguel, seja esse o medo de ter seu espaço invadido, o medo de aceitar sua sexualidade ou, ainda, o medo de ficar sozinho que a personagem revela quando consome seu outro: "Você vai correr dentro de mim. Vai estar sossegado em minhas veias, em meu coração. Não se preocupe, eu nunca vou abandonar você. Agora somos um só, como sempre deveríamos ter sido. Você nunca deveria ter se afastado de mim" (NAZARIAN, 2005, p.142). A luta por completude, no entanto, é justamente o que leva à sua desgraça final.

Padrões similares são encontrados em obras já mencionadas nesse trabalho como "William Wilson" e The picture of Dorian Gray. Comumente notamos um impulso destrutivo que é, na verdade, a busca pela recuperação do próprio eu, a exemplo do que se passa em "O Horla", de Guy de Maupassant (2016), em que o narradorpersonagem escreve em seu diário sobre uma presença invisível que o assombra e lhe causa um inexplicável mal-estar. A luta por aprisionar e aniquilar essa força desconhecida que perturba sua relação, antes aparentemente harmônica, com o local habitado escalona até levá-lo, por fim, a incendiar a própria casa com todos os empregados dentro. Esse ser inalcançável, a quem o narrador chama de Horla, no entanto, não perece no incêndio, o que leva a personagem a uma única conclusão: "sem dúvida... ele não 
está morto... Então... então... vai ser preciso que eu me mate!" (MAUPASSANT, 2016, p.277). Em todos esses textos, nota-se a figura de um duplo, seja ele um sósia, uma pintura ou um ser intocável, e, em todos os casos, a personagem busca, mais cedo ou mais tarde, a destruição desse outro que atormenta sua vida. Essa destruição, porém, culmina na ruína de si mesmo ou, como ocorre no conto de Maupassant, na compreensão de que não há outra saída senão tirar a própria vida. A completude jamais é alcançada.

Antes da destruição do fenômeno, no entanto, se é que ela ocorre, têm-se a percepção de que ele é indestrutivel. Miguel busca, por vezes e em vão, confrontar diretamente Thomas, chegando a tentar envenená-lo, mas o fenômeno parece sempre lhe escapar no último segundo: "Passava por debaixo da porta. Escorria pelo ralo. Corria pelo fio do telefone, do interfone" (NAZARIAN, 2005, p.91). O outro invade seu espaço, o observa, o incomoda, mas não se revela e é isso que lhe confere um caráter ainda mais perturbador. Apesar de seus atributos aparentemente sobre-humanos, "o fenômeno não precisa intervir concretamente. Ele só precisa estar lá e observar" (MALRIEU, 1992, p.95 - tradução nossa) ${ }^{12}$, como vemos em "O Horla". Em diversos momentos, o narrador do conto de Maupassant se sente vigiado e perseguido mesmo que esteja completamente sozinho: "De repente, achei que estava sendo seguido, que andavam atrás de mim, bem perto, quase me tocando. Virei-me bruscamente. Estava sozinho" (MAUPASSANT, 2016, p.255). O fenômeno é maior que a personagem, parece habitar um espaço-tempo muito além de sua compreensão e revela constantemente sua falibilidade.

12 Le phénomène n'a pas besoin d'intervenir concrètement. Il lui suffit d'être là, et de regarder. 
Na dialética da personagem e do fenômeno, se estabelece uma evidente relação de atração e repulsa. A personagem é inevitavelmente seduzida pelo fenômeno e o procura, mesmo que inconscientemente, como Alphonse procura o dedo da Vênus para depositar seu anel de casamento no conto "A Vênus de Ille", de Mérimée (2016). No momento em que isso ocorre, Alphonse estava jogando péla - um ancestral do jogo de tênis -, mas sente que o anel de diamantes que trazia no dedo, e que entregaria à noiva na hora do casamento, estava atrapalhando seu jogo. Decide, então, retirar o anel do dedo e, ao invés de entregá-lo ao narrador-personagem que se precipita para recebê-lo, vai até a estátua da Vênus e o coloca em seu dedo anelar. O ato impensado cria uma inquebrável ligação entre o jovem e a estátua. Logo depois, Alphonse tenta recuperar seu anel e, portanto, desvincular-se do fenômeno, mas isso já não é possível: "O dedo da Vênus está contraído, dobrado; ela aperta a mão, compreende?... É minha mulher, ao que parece, já que lhe dei meu anel... Ela não quer mais devolvê-lo" (MÉRIMÉE, 2016, p.134). Por fim, Alphonse é assassinado e, embora as circunstâncias da morte permaneçam obscuras ao fim da narrativa, uma das sugestões é de que a própria estátua tenha lhe tirado a vida numa espécie de sombria consumação de seu casamento.

Miguel também vive esse caso de amor e ódio com Thomas. Embora não se tenha conhecimento, no início da história, sobre a relação amorosa entre os dois, esse é um fator que indica a atração sentida pelo protagonista em relação ao outro. Miguel namorou Thomas e, portanto, o desejava. Mesmo sem qualquer lembrança de quem seja o invasor, a personagem o busca de forma incessante. Não há tentativa de fuga, mas de encontro - ou reencontro. Após 
ficar face a face um com o outro e Miguel se convencer de que Thomas é apenas parte da sua consciência, eles finalmente se unem por meio do sexo:

\begin{abstract}
Então sentiu os braços por trás, ao redor do seu corpo. Um beijo na nuca, o mesmo arrepio. Ele vinha e abraçava a si mesmo. Ele se agarrava e lhe dava um beijo. Virou-se e olhou nos seus olhos. Fechou-os e sentiu seu hálito. Sua barba crescendo, assim como seu membro. Sua língua em sua língua, seus lábios em seus lábios; mergulhou num beijo quente e se entregou. (NAZARIAN, 2005, p.116)
\end{abstract}

No dia seguinte, todavia, Miguel rejeita novamente Thomas, tenta fugir, mas retorna e, por último, aniquila o fenômeno e, de certo modo, a si mesmo. A repulsa nunca é suficiente para impedir que personagem e fenômeno compartilhem uma última comunhão e só então, enfim, cheguem ao término de sua relação, geralmente pelo extermínio de um deles ou de ambos. Mas por que o fenômeno incomoda tanto a personagem?

Em Feriado de mim mesmo, quando Miguel conversa com seu advogado, este lhe questiona diversas vezes quanto ao real motivo do assassinato, mas não se convence com os pequenos acontecimentos expostos pelo cliente, como a escova no banheiro e o arquivo em seu computador. O que ocorre é que, como afirma Furtado, diferentemente do que vemos no maravilhoso, "o Sujeito do fantástico [que é o fenômeno] é negativo" (1980, p.97). Considerando a posição do protagonista na história, o fenômeno não surge para ajudar a personagem, mas para atrapalhar, para se contrapor, para invadir seu espaço. O sósia do narrador de "William Wilson" arruína seus planos e, por isso, é negativo em 
relação ao protagonista por mais imorais que sejam os planos deste. Assim, Thomas se torna um opositor para Miguel no momento em que adentra seu apartamento e ali habita. Por isso mesmo, não é uma ação concreta contra a personagem que a leva a desejar destruir o fenômeno, mas sua simples presença, sua existência que contraria aquilo que a personagem toma como mais precioso em sua vida. Nesse sentido, muitas vezes, como se passa em Feriado, o protagonista é somente uma vítima aparente, pois "[m]esmo que o fenômeno represente, indiscutivelmente e sem ambiguidade, um perigo evidente para o indivíduo ou para o grupo, ele permanece, contra todas as aparências, uma vítima" (MALRIEU, 1992, p.103 - tradução nossa) ${ }^{13}$. O inocente Thomas perde a vida sem possuir qualquer culpa e sem entender de fato a razão, simplesmente porque sua própria existência o coloca em contradição à existência de Miguel.

\section{CONSIDERAÇÕES FINAIS}

A interação entre personagem e fenômeno, mesmo quando estas duas instâncias se encontram circunscritas em uma mesma figura e independente da perspectiva teórica adotada, se prova fundamental à constituição da narrativa fantástica. Essa interação vai muito além de um simples embate superficial e penetra profundamente na psicologia da personagem, causando transformações inesperadas e irreversíveis.

Feriado de mim mesmo se apropria dessa lógica ao contrapor uma personagem reclusa como Miguel a um outro que lhe invade um

13 Même lorsque le phénomène représente sans conteste et sans ambiguïté un danger évident pour l'individu ou pour le groupe, il n'en reste pas moins, contre toute apparence, une victime. 
espaço íntimo, cuidadosamente preservado de qualquer influência externa, acarretando em sérias transformações em sua natureza. Devido à sua posição social, a personagem ganha credibilidade frente ao leitor, o qual é levado, então, pela construção narrativa, a adotar seu ponto de vista, confiando no caráter aparentemente sobrenatural da manifestação enfrentada. Após o fim do romance, ao reavaliar as ações de personagem e fenômeno, se torna evidente que Thomas não se constitui em mais que uma ameaça ilusória e que o impacto de sua presença não reside em uma suposta intangibilidade, mas na duplicidade que ele representa. Thomas é uma parte de Miguel que ele insiste em negar, a prova concreta de um, ao mesmo tempo, temor e desejo: a sexualidade por ele reprimida. Deste modo, ainda que a personagem se recuse a reconhecer até o último momento a real natureza do outro, o contato entre ambos revela as contradições entre as diferentes facetas de Miguel, opondo a orientação heterossexual e o estilo de vida isolado com que a personagem se apresenta no início do romance à orientação homossexual e o estilo de vida mais sociável de quem partilha de um relacionamento amoroso.

Considerando essas observações e, ainda, a análise comparativa entre o romance de Nazarian e as diversas obras do século XIX aqui mencionadas, concluímos que Feriado de mim mesmo apresenta claramente a dialética entre personagem e fenômeno postulada por Malrieu, nos indicando sua possível cincunscrição no universo das narrativas fantásticas. Deste modo, este trabalho se estabelece como uma pequena parte do que pode vir a ser uma análise mais longa e detalhada do romance em questão, na qual se possa verificar mais a fundo as intersecções entre os procedimentos e temas típicos do fantástico e a obra de Santiago Nazarian. 


\section{REFERÊNCIAS}

BESSIÈRE, Irène (1974). Le récit fantastique: la poétique de I'incertain. Paris: Larousse.

CESERANI, Remo (2006). O fantástico. Nilton Cezar Tridapalli (Trad.). Londrina: Eduel.

DICKENS, Charles (2004). "O sinaleiro". In: CALVINO, Ítalo (Org.). Contos fantásticos do século XIX: o fantástico visionário e o fantástico cotidiano. São Paulo: Companhia das Letras.

FURTADO, Filipe (1980). A construção do fantástico na narrativa. Lisboa: Livros Horizonte.

JAMES, Henry (2005). "A volta do parafuso". In: MANGUEL, Alberto (Org.). Contos de horror do século XIX. São Paulo: Companhia das Letras.

KIPLING, Rudyard (1888-1890). "The phantom 'rickshaw". In: The phantom 'rickshaw and other tales. Allahabad: A. H. Wheeler \& Co.

MALRIEU, Joël (1992). Le fantastique. Paris: Hachette.

MAUPASSANT, Guy (2016). "O horla". In: COSTA, Flávio Moreira da (Org.). Os melhores contos fantásticos. Rio de Janeiro: Nova Fronteira.

MERIMÉE, Prosper (2016). “A Vênus de Ille”. In: COSTA, Flávio Moreira da (Org.). Os melhores contos fantásticos. Rio de Janeiro: Nova Fronteira.

NAZARIAN, Santiago (2005). Feriado de mim mesmo. São Paulo: Editora Planeta do Brasil.

POE, Edgar Allan (2016). "William Wilson". In: COSTA, Flávio Moreira da (Org.). Os melhores contos fantásticos. Rio de Janeiro: Nova Fronteira.

SANTOS, Adilson dos (2009). Um périplo pelo território duplo. In: Revista Investigações. Recife, 22(1), 51-101.

TODOROV, Tzvetan (1975). Introdução à literatura fantástica. Maria Clara Correa Castello (Trad.). São Paulo: Editora Perspectiva.

WELLS, Herbert George (2013) "O caso do finado Mr. Elvesham". In: CASARES, Adolfo Bioy; BORGES, Jorge Luis; OCAMPO, Silvina (Orgs.). Antologia da literatura fantástica. São Paulo: Cosac Naify.

WILDE, Oscar (2015.). The Picture of Dorian Gray. New York: Barnes \& Noble. 